\title{
WebQuest Technology as a Tool for the Formation of IT-Competence of Future Specialists
}

\author{
Emma N. Gilyazeva \\ Department of Philology \\ Kazan Federal University \\ Naberezhnye Chelny, Russia \\ emma.giljazeva@mail.ru
}

Leysan N. Bulanova

Department of Humanitarian and Social Disciplines

Kazan National Research Technical University named after

A.N. Tupolev-KAI

Naberezhnye Chelny, Russia

leisanbulanova@yandex.ru

\author{
Ilnara F. Khakimova \\ Department of Foreign Languages \\ Naberezhnye Chelny State Pedagogical University \\ Naberezhnye Chelny, Russia \\ ilnara7gab@mail.ru \\ Liliya R. Zakirova \\ Department of Foreign Languages \\ Naberezhnye Chelny State Pedagogical University \\ Naberezhnye Chelny, Russia \\ lzyouk@mail.ru
}

\begin{abstract}
The article is devoted to one of the topical issues of the modern system of higher education associated with the introduction of innovative forms of education - the formation of IT-competence of future specialists. The basis of this competence is the knowledge about the functioning, structure of the information environment and the skills necessary to interact with it by modern means of information technology. The aim of the work is to analyze the effectiveness of the WebQuest technology as a new pedagogical model of learning, contributing to the formation of IT-competence of future specialists. The pedagogical experiment conducted among the 2 nd year students allowed to check the possibility of using the WebQuest technology in teaching linguistic and cultural information in a language department, as well as to determine the effectiveness of web projects in teaching a second foreign language. The authors come to the conclusion that the use of the WebQuest technology in teaching foreign languages allows to intensify the time-limited learning process, clearly, quickly and structurally organize active research and creative activities of students, to consider the topics of linguistic and cultural nature, contribute to the formation of IT-competence of future specialists, thus contributing to the quality of education - the basis of sustainable economic development.
\end{abstract}

Keywords: education, foreign languages, modern Internet technologies, WebQuest technology

\section{INTRODUCTION}

Our country is involved in the global process of transition of civilization to a new post-industrial stage of its development, characterized by the diversification of multilevel vocational education, changing the previously dominant technological forms of activity to new ones - information technology, where the main product is information. Therefore, the system of training specialists cannot remain unchanged, it must comply with the logic and content of innovative processes taking place in Russian society and industry.

The task of formation and development of IT-competence is very important for universities in the preparation of future specialists $[1,2]$. The existing educational standards of higher education are based on the competence-based approach to training. The process of formation and development of professional competencies is considered as a means of achieving a new quality of education [3].

The basis of this competence is the knowledge about the functioning, structure of the information environment and the skills necessary to interact with it by modern means of information technology.

IT-competence is defined not only as an indicator of skills, abilities and knowledge that allow to quickly navigate in the global information space, but also as a certain experience in the evaluation, search, use and storage of data obtained with the help of modern information technologies, as the ability and readiness to solve practical and educational problems [4].

The analysis of the concept of IT-competence allows to draw a conclusion about the connection of this competence with project activities.

One of the forms of project activity on the basis of modern Internet technologies is the WebQuest technology, which is based on not very difficult, but problematic tasks [5]. Webquest is a web-task, which is a scenario of organization of project activities of students on any topic using Internet 
The term WebQuest was first proposed in the summer of resources and involves working with a large amount of material, research activities and critical understanding of information [6, 7]. Modern Internet technologies of the second generation (Web 2.0) allow users not only to find and download information, but also to work together and place new information on the network, create an open, interactive educational information environment.

The aim of the work is to analyze the effectiveness of the web quest technology as a new pedagogical model of learning, contributing to the formation of IT-competence of future specialists.

According to this goal, the following structure of the study was built:

1) an analyze of the scientific literature on the issue: studying of the concept of "Web Quest" and the structure of this technology; 2) experimentally verifying the pedagogical effectiveness of the proposed learning technology; 3) an assessment of the effectiveness of the WebQuest technology in teaching foreign languages.

\section{LITERATURE REVIEW AND RESEARCH METHODS}

\section{A. Research methods}

In order to solve the tasks the following methods were used:

- theoretical (study and analysis of linguistic, methodological and psychological-pedagogical literature in order to determine the scientific basis of the study);

- empirical (monitoring of educational activities of students in the process of teaching the second foreign language, conducting surveys, questionnaires, testing students);

- organizational (conducting a pedagogical experiment);

- methods of data processing (analysis and processing of data obtained during the study);

- $\quad$ interpretation (presentation of the research results).

\section{B. Literature review}

In recent decades, IT-competence is considered one of the most key characteristics in the training of future professionals in vocational education and is studied by many scientists.

The theoretical and methodological basis of the study on the formation of IT-competence were the works of prominent scientists on the following issues: 1) the concept of competence-based approach to professional training $[8,9,10$, 11 , etc.]; 2) the development of virtual educational space [12, 13,14 , etc.]; 3) e-learning technologies are presented in the studies of $[15,16,17,18$, etc. $]$.

The features of the web-quest technology are covered in the works of Aydin S [5], Kazakova O P, Klyoster A M [6], Dodge B [19, 20], March T [21, 22], Perez Torres I [23], Asunka S [24], Stetter M E, Hughes M T [25], Bahč M Ž [26], Polly D \& Ausband L [27], etc. 1995 by Bernie Dodge, a professor of educational technology at the University of San Diego (USA) [7]. The author developed innovative Internet applications for integration into the educational process when teaching various subjects at different levels of education. Web quests can cover a single problem, a subject, a topic, or be cross-subject.

B. Dodge identifies three principles for the classification of web quests:

1) By the duration of the implementation: short-term and long-term.

2) On the subject content: mono- and interdisciplinary.

3) By the type of tasks performed by students: retelling tasks, compilation tasks, mystery tasks, journalistic tasks, design tasks, creative product tasks, consensus building tasks, persuasion tasks, self-knowledge tasks, analytical tasks, judgment tasks, scientific tasks [7].

The task is the most important part of the WebQuest. It is the main purpose of the student's work on the project, it directs the actions of the quest participants and encourages them to perform the tasks laid down in the project by its creator - the teacher [19]. A good task should be feasible and fun, encourage students to think and improve themselves [7]. The development of WebQuests is based on the technology of project training in order to attach students to independent research, creative activity.

Based on the work of B. Dodge "Some thoughts about WebQuest", we can distinguish some structural elements of the WebQuest:

1. An introduction that creates a base and provides some background information;

\section{A task that is feasible and interesting;}

3. A set of information sources required to complete a task.

4. Description of the process of students' activities, which they must carry out to solve the task. The process of activity should be broken down into clearly described steps;

5. Some recommendations on how to organize the information obtained on the Internet;

6. A conclusion made by students at the end of a search; a generalization of what they have learned [7].

As criteria for evaluating a web quest, B. Dodge advises to use: originality of the work, its research character, quality of argumentation, manifestation of the ability to work in a group, quality of written text, quality of oral presentation (presentation), etc. [20].

Description of various educational WebQuests [5, 6, 22, $23,25,26]$ allows to distinguish among them, first of all, gaming and research. Game WebQuests can be educational in nature, as they contribute to gain with a certain set of language knowledge. They are aimed at junior students, the form of information is playful. Research WebQuests, on the contrary, allow to carry out deepening of the knowledge studied by students, i.e. focused only on one category of students, namely 
linguistic and cultural information about the countries of the studied language - Germany, Austria and Switzerland.

Below is an example of using the WebQuest technology on the example of the topic "Deutschland von Stadt zu Stadt" and the course of the experimental training of second-year students of the language department of Kazan Federal University (branch in Naberezhnye Chelny).

The main objectives of the experiment were the following:

1) to check the possibility of using the WebQuest technology in teaching linguistic and cultural information in a language department;

2) to determine the effectiveness of web projects in teaching a second foreign language.

Diagnosis and assessment of the level of formation of foreign language socio-cultural competence of students in the experiment was carried out by testing and questioning students. The objects of control were the knowledge of background vocabulary, country knowledge, information relevant to the theme of the project, as well as the motivation of students to study a second foreign language and the use of computer technology in the study of foreign languages and cultures.

For the experiment we have chosen 2 groups -4 subgroups of second-year students (total number - 49 students). For the experiment, we created a medium-term (10 days) WebQuest on the topic "Deutschland von Stadt zu Stadt".

All subgroups were divided into eight competing subgroups of 6 people.

Each subgroup received the same task and had to complete it within the prescribed period - 10 days. The work was to be carried out by students independently and out-of-class, and the role of the teacher at this stage was limited to control and advisory actions.

Our WebQuest was made in accordance with the scheme described in paragraph 3 , and consisted of six main sections:

1) Introduction;

2) Task;

3) Description of the process of working on a quest and guidelines for the organization of the information obtained (Process);

4) Resources - links to the thematic sites selected by the teacher;

5) Scheme of evaluation of the results of student work (Evaluation);

6) Conclusion.

According to the "legend", the students were employees of a large travel company and had to prepare for a major client who, due to insufficient time, could visit only two cities in Germany, the best report with a presentation telling about the sights and interesting facts of the chosen city. this regard, in the practical classes of the second foreign language, the WebQuest technology within the project method was used for the study of certain topics closely related to 
information about cultural realities, 3-6 points - a few mistakes, average pronunciation, little information about cultural realities, 7-10 points - good performance in all three parameters; 4) quality of multimedia presentation: 0-2 points no valuable cultural facts, few illustrations, 3-6 points - there are some cultural facts of interest, there are interesting illustrations, 7-10 - the presentation showed effective creative work of the group, rich in multimedia information illustrating cultural realities.

The results of the evaluations of the eight groups against the above criteria are presented in the figure below. With a maximum score of 33 , the groups showed sufficient quality results of the task ( $\max .-31$ points, min. -23 points). The reports of groups 3 and 8 (Magdeburg and Bremen) were rated as the best. pages were deliberately not classified by content, which made it necessary for each member of the group, regardless of the role assigned to him, to view and process all the information related to the theme of the WebQuest, and not be limited only to his narrow task.

\section{RESULTS}

The result of the study was the development of linguisticcultural WebQuest projects on the topics included in the program of the practical course of the second foreign language, the testing of which in practice showed high efficiency of their use in the formation of linguistic-cultural knowledge of students-linguists.

During the experiment, it was found that the main results of the use of WebQuests in teaching a foreign language and culture are: 1) improving the level of knowledge of the realities of culture, traditions, habits and customs of the people of the country of the studied language; 2) increasing the vocabulary of students through linguo-cultural vocabulary; 3 ) increasing the motivation of students to study a foreign language culture; 4) increasing the motivation of students to use computer technology in their educational activities, thus contributing to the formation of IT-competence.

Observation of students showed that work with the use of the Internet is performed by students with great enthusiasm and high motivation. Tasks that in the traditional performance might seem boring and uninteresting to students, acquire a new attractive coloring in integrating them with modern information technologies. Keep your text and graphic files separate until after the text has been formatted and styled. Do not use hard tabs, and limit use of hard returns to only one return at the end of a paragraph. Do not add any kind of pagination anywhere in the paper. Do not number text headsthe template will do that for you.

\section{DISCUSSION}

Evaluation of the quality of the project was carried out according to the following criteria: 1) the degree of cooperation shown within the subgroup: 0-2 points - small, 36 - medium, 7-10 - good; 2) the use of additional materials not presented in the "Resources" section: 0 points - no, 2 - little, 3 - enough; 3 ) the quality of oral speech: $0-2$ points - a lot of grammatical errors, poor pronunciation, no valuable

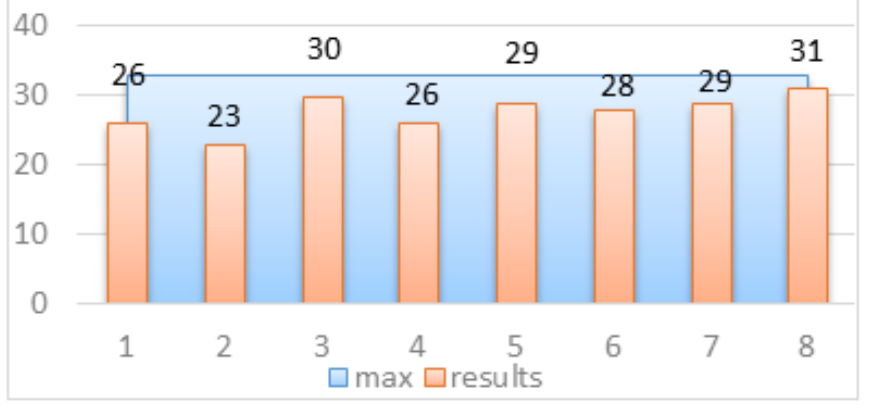

Fig. 1. The results of the evaluations of the projects of the eight groups

In order to assess the identification of the effectiveness of testing the WebQuest technology, a survey was conducted.

The developed questionnaire included 6 points aimed at studying students' opinions the WebQuest technology, which were compiled using the Likert scale. The Likert scale was first proposed in 1932 by the American expert in the fields of organizational psychology and management Rensis Likert. This scale was developed by him during his postgraduate studies at Columbia University. Since then, this scale has been widely used to measure the attitude of respondents to the subject of the study. This method assumes that the respondent expresses his agreement or disagreement with each judgment (from the proposed set).

The "classical" Likert scale has 5 points. Ratings on the Likert scale can be expressed in categories of consent, frequency, importance, quality, etc., for example: (5) Strongly agree - (4) Agree - (3) Neutral attitude - (2) Disagree - (1) Strongly disagree; (5) Always - (4) Very often - (3) Sometimes - (2) Rarely - (1) Never; (4)Very important - (3) (5)Very good - (4) Good - (3) Acceptable - (2) Bad - (1) Very bad [13, 14].In our study, students were required to evaluate the effectiveness of the inverted learning methods relative to the traditional method of learning, and also to express an opinion on the readiness to continue training in this new way. In the questionnaire, it was proposed to express their agreement or disagreement with the proposed statements on a 5-point scale of the following content: 1 - point meant "completely disagree"; 2 - "partially disagree"; 3 - "it is important - (2) To some extent important - (1) Unimportant; 
difficult to say, agree or disagree"; 4 -"partially agree"; 5 "fully agree". All 20 students of the experimental group participated in the survey. Due to the small number of participants, it was decided not to carry out statistical processing of the results of these questions, compiled using the Likert scale, presenting them in Table I.

TABLE I. ANALYSIS OF THE RESULTS OF THE SURVEY

\begin{tabular}{|l|l|l|l|l|l|}
\hline Statements & $\mathbf{1}$ & $\mathbf{2}$ & $\mathbf{3}$ & $\mathbf{4}$ & $\mathbf{5}$ \\
\hline $\begin{array}{l}\text { The learning process for previous } \\
\text { lessons on the "WebQuest" } \\
\text { technology was more effective than } \\
\text { the traditional method (reading the } \\
\text { texts on the lesson and discussing } \\
\text { them). }\end{array}$ & 5 & 4 & 11 & 17 & 12 \\
\hline $\begin{array}{l}\text { The preparation of the report and } \\
\text { presentation as part of testing the } \\
\text { "WebQuest" technology required } \\
\text { more time than was provided by the } \\
\text { teacher. }\end{array}$ & 14 & 6 & 7 & 9 & 13 \\
\hline $\begin{array}{l}\text { The use of the "WebQuest" } \\
\text { technology motivates to better } \\
\text { assimilation of the material due to the } \\
\text { ability to use additional Internet } \\
\text { sources. }\end{array}$ & & 6 & 9 & 13 & 21 \\
\hline $\begin{array}{l}\text { The "WebQuest" technology allows } \\
\text { you to learn the material better than } \\
\text { the traditional method of learning. }\end{array}$ & - & 5 & 9 & 16 & 19 \\
\hline I liked the "WebQuest" technology & 2 & 5 & 6 & 24 & 12 \\
\hline $\begin{array}{l}\text { I would like to continue learning the } \\
\text { "WebQuest" technology in the future. }\end{array}$ & 3 & 4 & 13 & 20 & 9 \\
\hline
\end{tabular}

In general, students are quite positive about the new method of teaching, noting the higher efficiency of classes on the WebQuest technology. Diligent students noted that the preparation for classes by the method of "WebQuest" requires more time. More than half of the participants in the experiment assessed their diligence by putting "good", using the proposed descriptors. The conversation with the students of the experimental groups showed that the project participants really worked on it with great enthusiasm and high motivation. Many of the students expressed their wishes to the teachers, often engage in such activities.

The WebQuest technology has shown its effectiveness in the short-term pedagogical impact on the experimental groups.

\section{CONCLUSION}

Thus, the use of the WebQuest technology in teaching foreign languages allows to intensify the time-limited learning process, clearly, quickly and structurally organize active research and creative activities of students, to consider the topics of linguistic and cultural nature, contribute to the formation of IT-competence of future specialists, thus contributing to the quality of education - the basis of sustainable economic development. In addition, the WebQuest technology makes the educational process more diverse, lively and efficient.

WebQuest is a unique opportunity to use the World Wide Web for teaching and learning. WebQuest allows students to make discoveries, increases self-confidence, and awakens interest and self-esteem of students.

\section{REFERENCES}

[1] S. G. Coria, "An approach to the development of didactic competences for the promotion of the motivation for reading in students of the Bachelor in Pedagogy", Pedagogical research proposal, Dilemas contemporaneos-educacion politica y valores, Mexico, vol. 6, iss. 1, 2018, 5 p.

[2] K. A. Wentzel, "Competence-in-context approach to understanding motivation at school", Research on Sociocultural Influences on Motivation and Learning: Big theories revisited 2: Information Age Publishing-IAP, USA, 2018, pp. 193-212.

[3] Y. F. Zhu and R. Hu, "Research and Analysis on English Teaching Reform in Higher Vocational Colleges from the Perspective of Professional Competence Cultivation", 4th International Conference on Education, Management and Information technology (ICEMIT 2018), FRANCIS ACAD PRESS, England, 2018, pp. 763-766.

[4] J. Gebhardt, "Netcompetence - a sustainable need for the digitized working world and society", 3rd International Conference on Lifelong Education and Leadership for All (ICLEL), Turkey, 2017, pp. 216-226.

[5] S. Aydin, "WebQuests as language-learning tools", Computer Assisted Language Learning, 29 (4), 2016, pp. 765-778.

[6] O. P. Kazakova and A. M. Klyoster, "Educational tasks modelling on the basis of the web-quest technology (from the experience of teaching Foreign Languages)", Astra Salvensis, 6, 2018, pp. 699-708.

[7] B. Dodge, "Some Thoughts About Web Quests" [Electronic resource]. Available at: http://webquest.sdsu.edu/about_webquests.html (Accessed: 06 September 2018).

[8] A. Bilyalova, "ICT in Teaching a Foreign Language in High School", Procedia, Social and Behavioral Sciences, 2017, pp. 175-181.

[9] M. Rieckmann, "Learning to transform the world: Key competencies in Education for Sustainable Development", Issues and trends in education for sustainable development, In A. Leicht, J. Heiss and W.J. Byun (Eds), Issues and trends in education for sustainable development, Paris: UNESCO, 2018, pp. 39-59.

[10] D. Leutner, J. Fleischer, J. Grünkorn, and E. Klieme, "Competence Assessment in Education Research", Models and Instruments"Springer International Publishing AG, 2017, 503 p.

[11] M. Spante, S. S. Hashemi, M. Lundin, and A. Algers, "Digital competence and digital literacy in higher education research: Systematic review of concept use", Cogent Education, Taylor and Francis, 2018, $5: 1$.

[12] C. Schott, S. Marshall, "Virtual reality and situated experiential education: A conceptualization and exploratory trial", Journal of computer assisted learning, vol. 34, issue 6, 2018, pp. 843-852.

[13] J. R. Domingo and E. G. Bradley, "Education Student Perceptions of Virtual Reality as a Learning Tool", Journal of Educational Technology Systems, 46 (3), 2018, pp. 329-342.

[14] C. Girvan, "What is a virtual world? Definition and classification", Educational Technology Research and Development, vol. 66, issue 5, 2018, pp. 1087-1100.

[15] H. Xie, D. Zou, R.. Zhang, M. Wang, and R.Kwan, "Personalized word learning for university students: a profile-based method for e-learning systems", Journal of Computing in Higher Education, 31 (2), 2019, pp. 273-289.

[16] I. Golitsyna, "Application of web services in teaching of IT-discipline", Procedia - Social and Behavioral Sciences, vol. 214, 2015, pp. 578-585.

[17] O. Golubev and V.Testov, "Network Information Technologies as a Basis of New Educational Paradigm", Social and Behavioral Sciences, vol. 214 (5 Dec. 2015), 2015, pp. 128-134.

[18] N. Selwyn and S. Gorard, "Students' use of Wikipedia as an academic resource - Patterns of use and perceptions of usefulness", The Internet and Higher Education, 28, 2016, pp. 28-34. 
[24] S. Asunka, "Using the webquest approach to elicit student engagement in a university course: A case study", Student Engagement and Participation: Concepts, Methodologies, Tools, and Applications, 1, 2017, pp. 454-478.

[25] M. E. Stetter, M. T. Hughes, "Using webquests to promote reading comprehension for students with learning disabilities", International Journal of Special Education, 32 (3), 2017, pp. 608-617.

[20] B. Dodge, "A Rubric for Evaluating WebQuests" [Electronic resource]. Available at: http://webquestsdsu.edu/webquestrubric.html (Accessed: 06 September 2018).

[21] T. March, "What's on the Web? Sorting Strands of the World Wide Web for Educator"s [Electronic resource]. Available at: September 2018).

[22] T. March, "The 3 R's of WebQuests: Let's keep them Real, Rich, and Relevant", Multimedia schools, vol. 7, no. 6, 2004, pp. 62-67.

[23] I. Perez Torres, "A Model WebQuest for Teaching and Learning an L2" [Electronic resource]. Available at: http://www.isabelperez.com/webquest/taller/12/english/handout_wq_12_ en.pdf.

[26] M. Ž. Bahč, "Webquests in foreign language learning", Webquests beim fremdsprachenlernen, Informatologia, 49 (3-4), 2016, pp. 203-211.

[27] D. Polly, L. Ausband, "Developing Higher-Order Thinking Skills through WebQuests", Journal of Computing in Teacher Education, 26 (1), 2014, pp. 29-34.

[28] E. Stockwell, "Using web-based exploratory tasks to develop intercultural competence in a homogeneous cultural environment", Innovations in Education and Teaching International, 53 (6), 2016, pp. 649-659. 